\title{
Molecular Structure-Affinity Relationship of Flavonoids in Lotus Leaf (Nelumbo nucifera Gaertn.) on Binding to Human Serum Albumin and Bovine Serum Albumin by Spectroscopic Method
}

\author{
Xiaosheng Tang ${ }^{1}$, Ping Tang ${ }^{2,3}$ and Liangliang Liu ${ }^{2, *}$ \\ 1 Hubei Key Laboratory of Edible Wild Plants Conservation and Utilization \& National Demonstration Center \\ for Experimental Biology Education \& College of Life Sciences, Hubei Key Laboratory of Pollutant Analysis \\ \& Reuse Technology, Hubei Normal University, Huangshi 435002, China; xiaoshengtang@yahoo.com \\ 2 Institute of Bast Fiber Crops, Chinese Academy of Agricultural Sciences, Changsha 410205, China; \\ pingtang@yahoo.com \\ 3 School of Environmental Science and Engineering, Hubei Polytechnic University, Hubei Key Laboratory of \\ Mine Environmental Pollution Control and Remediation, Huangshi 435003, China \\ * Correspondence: liuliangliang@caas.cn; Tel.: +86-731-8899-8525
}

Received: 3 May 2017; Accepted: 20 June 2017; Published: 23 June 2017

\begin{abstract}
Lotus leaf has gained growing popularity as an ingredient in herbal formulations due to its various activities. As main functional components of lotus leaf, the difference in structure of flavonoids affected their binding properties and activities. In this paper, the existence of 11 flavonoids in lotus leaf extract was confirmed by High Performance Liquid Chromatography (HPLC) analysis and 11 flavonoids showed various contents in lotus leaf. The interactions between lotus leaf extract and two kinds of serum albumins (human serum albumin (HSA) and bovine serum albumin (BSA)) were investigated by spectroscopic methods. Based on the fluorescence quenching, the interactions between these flavonoids and serum albumins were further checked in detail. The relationship between the molecular properties of flavonoids and their affinities for serum albumins were analyzed and compared. The hydroxylation on 3 and $3^{\prime}$ position increased the affinities for serum albumins. Moreover, both of the methylation on $3^{\prime}$ position of quercetin and the $C_{2}=C_{3}$ double bond of apigenin and quercetin decreased the affinities for HSA and BSA. The glycosylation lowered the affinities for HSA and BSA depending on the type of sugar moiety. It revealed that the hydrogen bond force played an important role in binding flavonoids to HSA and BSA.
\end{abstract}

Keywords: bovine serum albumin; flavonoids; fluorescence spectroscopy; human serum albumin; interaction; lotus leaf

\section{Introduction}

Flavonoids are a kind of antioxidant abundant in human diet and widespread in plants. Investigations of flavonoids from dietary have attracted great interests because of their bioactivities such as antioxidant activity, enzyme inhibitory activity, antitumor activity, and so on [1,2]. Most of their bioactivities are basically related to their antioxidant abilities. The structural differences of flavonoids significantly affect their absorption, metabolism, and activity in vivo [3,4]. While, the different structures of flavonoids come from various patterns of substitution through hydroxylation, methoxylation, sulfonation, acylation, prenylation, or glycosylation [5,6].

Lotus (Nelumbo nucifera Gaertn.) is a perennial aquatic plant widely distributed in eastern Asia, especially in China, India and Japan. The leaf, root, and seed of lotus were usually used as vegetables and medicines in China [7]. In recent years, the lotus leaf was becoming more and more popular as 
a kind of drink like tea in single form or as an ingredient in herbal formulations [8,9]. The lotus leaf was used in the treatment of sunstroke, diarrhea, and fever [10]. Modern studies also showed it possesses many pharmacological effects like anti-hyperlipidemia, anti-obesity, antioxidant, and anti-microbial activities [11-13]. Flavonoids are main functional components of lotus leaf and many of them were identified, including isoquercetin, hyperin, kaempferol, astragalin, myricetin, and so on [14-17].

Nowadays, investigations on the interaction between flavonoids and proteins garner great interest [18-20]. As one of the most abundant proteins in the circulatory system, serum albumins are the major transport protein in blood and can reversibly bind to small molecules like fatty acids, amino acids, drugs, and inorganic ions [21]. The bioavailability of many active compounds is related to the interaction and successive binding with serum albumins [22]. Forming stable binding complexes could be considered a suitable model for gaining various information of protein binding [23]. Human serum albumin (HSA) consists of a non-glycosylated single chain containing 585 amino acids with a molecular weight of 66,500 Da [24]. Three homologous domains (domains I-III), in turn divided into two subdomains (A and B), with multiple ligand-binding sites localized in each of these subdomains were described [20,25]. Many drugs bind to one of the two primary binding sites located in subdomains IIA and IIIA (Sudlow sites I and II, respectively) [26]. As the most prominent one, the IIA subdomain appears to be spacious. However, the IIIA site is smaller and less flexible and only structurally similar ligands could be accommodated. Bovine serum albumin (BSA) is a globular protein like HSA and has about $76 \%$ structural homology to HAS $[27,28]$. Considering the representative characteristics and the availability, the purified HSA and BSA are usually used as modeling proteins to investigate the interactions between small molecules and serum albumins. Binding of flavonoids to HSA was extensively studied using different fluorescence spectroscopy techniques [29-33]. The observed change in fluorescence enables the calculation of HSA-ligand complexes stability constants and also the distance between the ligand and Trp 214 [26]. Many studies reported the binding between flavonoids and serum albumins [34]. The structure-affinity relationship of flavonoids with serum albumins was studied as well. However, few reports have focused on the binding to the two kinds of serum albumins (HSA and BSA). The selection of flavonoids was various. Several reports were focused on the dietary flavonoids, while some reports selected different structures of flavonoids for comparison $[35,36]$.

In this paper, 11 flavonoids were chosen as the investigation samples based on our previous research, which were reported existing in lotus leaf and showed similar structures. The contents of 11 flavonoids in lotus leaf extract were confirmed by High Performance Liquid Chromatography (HPLC) method. Furthermore, the interactions between lotus leaf extract and two kinds of serum albumins (human serum albumin (HSA) and bovine serum albumin (BSA)) were carried out by spectroscopic methods and then the interactions between these 11 flavonoids and serum albumins (HSA and BSA) were further investigated in detail. Then the relationship between the molecular properties of flavonoids and their affinities for HSA and BSA were analyzed and compared.

\section{Results and Discussion}

\subsection{Analysis of Flavonoids in Lotus Leaf Extracts}

In order to understand the composition and content of selected flavonoids in lotus leaf extracts, the detail contents of 11 flavonoids in lotus leaf extracts were analyzed using HPLC. Eleven flavonoids - astragalin (1), rutin (2), hyperoside (3), isoquercitrin (4), taxifolin (5), luteolin (6), quercetin (7), apigenin (8), naringenin (9), kaempferol (10), and isorhamnetin (11) —were quantified with the standards in this study. The HPLC analysis provided a reproducible, well separated and detected method for the 11 flavonoid compounds [37]. The representative chromatograms of the standard mixture solution and lotus leaf extracts are illustrated in Figure 1. 


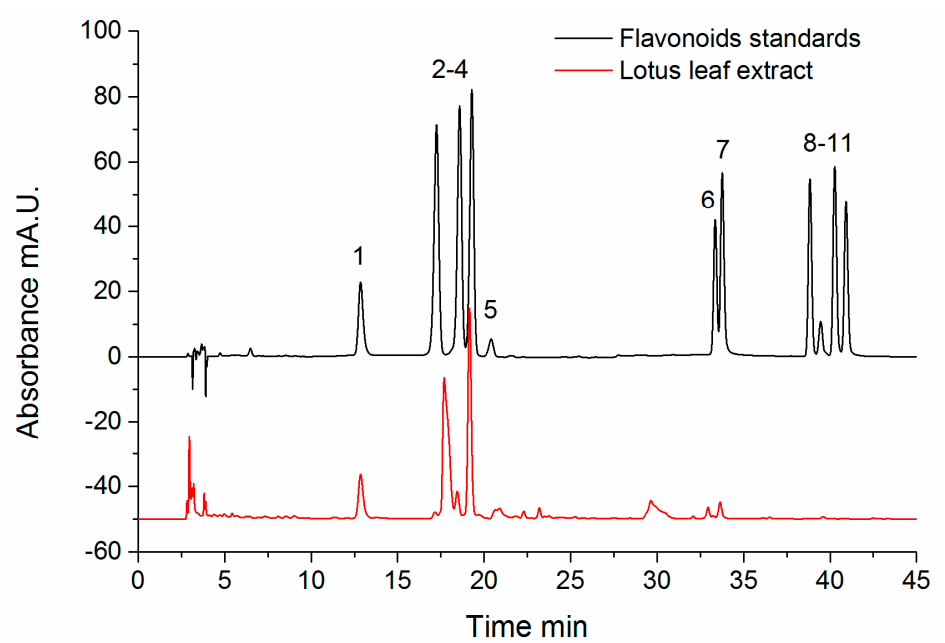

Figure 1. The chromatograms of standard mixture solution and lotus leaf extracts. The marked 11 flavonoids were astragalin (1), rutin (2), hyperoside (3), isoquercitrin (4), taxifolin (5), luteolin (6), quercetin (7), apigenin (8), naringenin (9), kaempferol (10), and isorhamnetin (11).

It could be observed that 11 flavonoids were well separated at a retention time ranging from $12.86 \mathrm{~min}$ to $40.90 \mathrm{~min}$. The quantitative analysis of each compound was accomplished by analyzing each standard compound with various concentrations. Based on the comparison of retention time, the contents of 11 flavonoids in lotus leaf extract were presented in Table 1. According to the HPLC results, astragalin, taxifolin, and isoquercitrin were abundant in lotus leaf extract (the contents of astragalin, taxifolin, and isoquercitrin were $13.347 \pm 0.150,10.597 \pm 0.240$, and $29.778 \pm 0.180 \mathrm{mg} / \mathrm{g}$ of lotus leaf sample, respectively). However, apigenin, luteolin, kaempferol and isorhamnetin showed relatively low content in lotus leaf extract (less than $1.0 \mathrm{mg} / \mathrm{g}$ ). Considering the selected flavonoids were reported by different literatures, the extraction using different solvents or different varieties and parts of lotus could result in the difference of contents of these flavonoids [38-41].

Table 1. Chemical structures of investigated flavonoids and their contents in lotus leaf extract.<smiles>O=c1cc(-c2ccccc2)oc2ccccc12</smiles>

\begin{tabular}{cccccc}
\hline \multirow{2}{*}{ Flavonoids } & \multicolumn{3}{c}{ Substitutions } & \multirow{2}{*}{ Retention Time (min) } & \multirow{2}{*}{ Content (mg/g) } \\
\cline { 2 - 4 } & $\mathbf{O H}$ & $\mathbf{O C H}_{\mathbf{3}}$ & Others & & \\
\hline Apigenin & $5,7,4^{\prime}$ & & & 38.84 & $0.216 \pm 0.022$ \\
Naringenin & $5,7,4^{\prime}$ & & Flavanone & 39.46 & $1.446 \pm 0.012$ \\
Luteolin & $5,7,3^{\prime}, 4^{\prime}$ & & & 33.36 & $0.491 \pm 0.039$ \\
Kaempferol & $3,5,7,4^{\prime}$ & & & 40.27 & $0.063 \pm 0.009$ \\
Astragalin & $5,7,4^{\prime}$ & & 3-O-glucoside & 12.86 & $13.347 \pm 0.150$ \\
Quercetin & $3,5,7,3^{\prime}, 4^{\prime}$ & & & 33.77 & $2.628 \pm 0.058$ \\
Taxifolin & $3,5,7,3^{\prime}, 4^{\prime}$ & & Flavanone & 20.41 & $10.597 \pm 0.240$ \\
Isorhamnetin & $3,5,7,4^{\prime}$ & \multirow{2}{*}{$\quad$} & & 40.92 & $0.390 \pm 0.043$ \\
Isoquercitrin & $5,7,3^{\prime}, 4^{\prime}$ & & 3-O-glucoside & 19.29 & $29.778 \pm 0.180$ \\
Hyperoside & $5,7,3^{\prime}, 4^{\prime}$ & & 3-O-galactoside & 18.58 & $3.292 \pm 0.055$ \\
Rutin & $5,7,3^{\prime}, 4^{\prime}$ & & 3-O-rutinoside & 17.25 & $1.588 \pm 0.045$ \\
\hline
\end{tabular}




\subsection{Quenching Effects of Lotus Leaf Extract and Flavonoids on HSA and BSA Fluorescence}

The fluorescence spectra of HSA and BSA with addition of lotus leaf extracts were investigated and the results were shown in Figure 2. As shown in Figure 2a, the lotus leaf extract exhibited the emission of fluorescence at $390 \mathrm{~nm}$ (Blue line in Figure 2a) and it apparently quenched the fluorescence of HSA (Pink line in Figure 2a). According to the reduction of background fluorescence introduced by the extract, the fluorescence quenching of HSA and BSA with addition of lotus leaf extract in different concentrations were completed (Figure 2b,c). The Stern-Volmer plots for HSA and BSA fluorescence quenched by lotus leaf extract were also calculated (insets in Figure $2 b, c)$. The Stern-Volmer plots were linear and the fitting degree $\left(R^{2}\right)$ was 0.976 for HSA and 0.983 for BSA. Considering the complex compositions of lotus leaf extract, the obtained fitting degrees were acceptable and detail investigations on 11 flavonoids were further conducted.
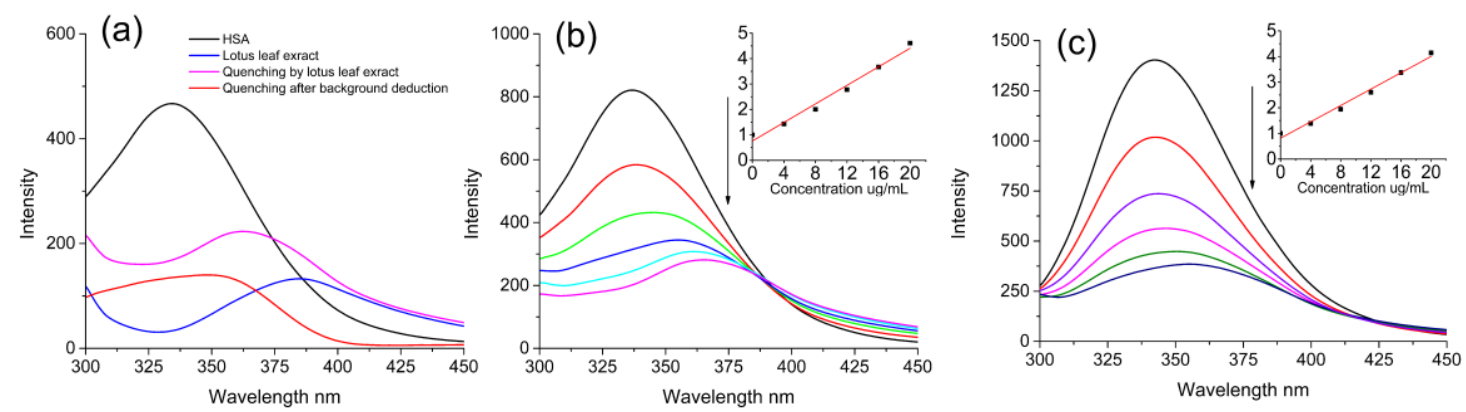

Figure 2. (a) The fluorescence spectra of human serum albumin (HSA) and lotus leaf extract; the quenching effects of lotus leaf extract on HSA fluorescence spectra and the Stern-Volmer plots for HSA (b) at $300.15 \mathrm{~K}$; the quenching effects of lotus leaf extract on bovine serum albumin (BSA) fluorescence spectra and the Stern-Volmer plots for BSA (c) at $300.15 \mathrm{~K}$. $\lambda_{\mathrm{ex}}=280 \mathrm{~nm}$; HSA and BSA, $10 \mu \mathrm{mol} / \mathrm{L}$; the addition of sample was 4.00, 8.00, 12.00, 16.00 and $20.00 \mathrm{mg} / \mathrm{L}$ of lotus leaf extract.

The fluorescence spectra of HSA and BSA with addition of apigenin, naringenin, luteolin, kaempferol, astragalin, quercetin, taxifolin, isorhamnetin, isoquercitrin, hyperoside, and rutin were measured. All tested samples could apparently quench the fluorescence of HSA and BSA with increasing concentrations. No obvious shifts of the maximum $\lambda_{\mathrm{em}}$ of HSA and BSA fluorescence for tested samples were observed. The decreases of fluorescence intensity varied with the kinds of samples. For instance, the addition of apigenin, kaempferol, and quercetin showed rapid quenching on HSA. The addition of apigenin made the fluorescence intensities of BSA decreased sharply. However, astragalin and rutin showed lower quenching rates on HSA and BSA. These results indicated that the quenching effect of flavonoids on HSA and BSA fluorescence depended on the structures of flavonoids [2].

In order to further investigate the difference, the Stern-Volmer plots for HSA and BSA fluorescence quenched by flavonoids samples were studied and calculated. As shown in Figure 3, the Stern-Volmer plots of these flavonoids were linear and the fitting degree $\left(R^{2}\right)$ (ranging from 0.990 to 0.999) were satisfied, which implied that the calculations of $K_{\mathrm{sv}}$ and $K_{\mathrm{q}}$ according Equation (1) were suitable. The quenching could be considered initiated by static quenching if $K_{\mathrm{q}}$ is much greater than $2.0 \times 10^{10} \mathrm{~L} / \mathrm{mol} / \mathrm{s}$ [42]. As shown in Table 2, the calculated $K_{\mathrm{q}}$ values of HSA and BSA fluorescence quenching by flavonoids were much higher than $2.0 \times 10^{10} \mathrm{~L} / \mathrm{mol} / \mathrm{s}\left(0.827 \times 10^{14} \mathrm{~L} / \mathrm{mol} / \mathrm{s}\right.$ to $4.695 \times 10^{14} \mathrm{~L} / \mathrm{mol} / \mathrm{s}$ for HSA and $0.731 \times 10^{14} \mathrm{~L} / \mathrm{mol} / \mathrm{s}$ to $3.710 \times 10^{14} \mathrm{~L} / \mathrm{mol} / \mathrm{s}$ for BSA). It could be concluded that the fluorescence quenching of HSA and BSA by flavonoids was probably initiated by static quenching [31]. 

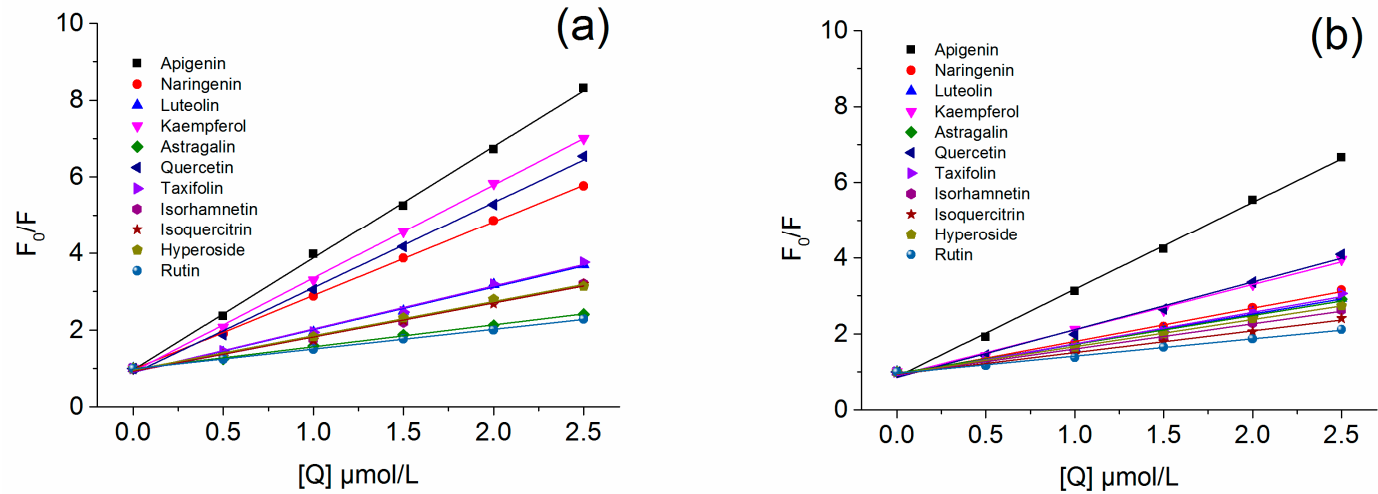

Figure 3. The Stern-Volmer plots for (a) HSA and (b) BSA fluorescences quenching by apigenin, naringenin, luteolin, kaempferol, astragalin, quercetin, taxifolin, isorhamnetin, isoquercitrin, hyperoside, and rutin at $300.15 \mathrm{~K}$.

\subsection{The Binding Constants and the Number of Binding Sites}

The binding constant $\left(K_{\mathrm{a}}\right)$ and the number of binding sites per protein molecule $(n)$ were calculated according to Equation (2) and shown in Table 2. The values of $\log K_{\mathrm{a}}$ was proportional to the number of binding sites $(n)$ for the interaction, which indicated that the Equation (2) used in this study was suitable for the investigation of interaction between flavonoids and serum albumins. The fitting degree $\left(R^{2}\right)$ (ranging from 0.993 to 0.999$)$ of the calculated binding constant $\left(K_{\mathrm{a}}\right)$ and the number of binding sites $(n)$ were satisfied for this experiment. The magnitudes of apparent binding constants for HSA and BSA were respectively in the range of $10^{5}$ to $10^{7} \mathrm{~L} / \mathrm{mol}$ and $10^{6}$ to $10^{7} \mathrm{~L} / \mathrm{mol}$.

\subsection{Influence of Structural Alteration of Flavonoids on Their Affinities for HSA and BSA}

\subsubsection{Hydroxylation and Methylation}

The effects of hydroxylation and methylation of flavonoids on the affinities for HSA and BSA were shown in Table 3. It could be concluded that the hydroxylation on position 3 and/or $3^{\prime}$ of flavonoids improved the affinities for HSA and BSA. However, the methylation on the $3^{\prime}$ position of quercetin decreased the affinity as well. These results indicated that the hydroxyl group was particularly important for flavonoids in binding to HSA and BSA [3]. The result was in accordance with the previous report that the binding constants and the number of binding sites between flavonoids and HSA or BSA increased with the increased hydroxyl groups $[43,44]$. The affinities of luteolin and quercetin for HSA were about 7.9 and 6 times higher than that of apigenin and kaempferol.

\subsubsection{Glycosylation}

The effect of glycosylation of flavonoids on the affinities for HSA and BSA were investigated. As shown in Table 3, the glycosylation at the 3 position of flavonoids decreased the affinities for HSA and BSA. The glycosylation of flavonoids decreased the affinities for serum albumins by 1 to 2 orders of magnitude, depending on the type of sugar moiety (glucoside, galactoside, and rutinoside). For instance, quercetin showed 3.20 times higher affinity than that of isoquercitrin, 1.94 times higher affinity than that of hyperoside and 15.60 times higher affinity than that of rutin in the interaction with HSA. While in the interaction with BSA, quercetin showed 1.60 times higher affinity than that of isoquercitrin, 2.56 times higher affinity than that of hyperoside, and 4.10 times higher affinity than that of rutin. This result was similar to the previous reports that the glycosylation of dietary polyphenols decreased the affinities for total plasma proteins [45]. 
Table 2. The affinities of 11 flavonoids for human serum albumin (HSA) and bovine serum albumin (BSA).

\begin{tabular}{|c|c|c|c|c|c|c|c|c|c|c|c|c|}
\hline \multirow{2}{*}{ Flavonoids } & \multicolumn{6}{|c|}{ HSA Affinity } & \multicolumn{6}{|c|}{ BSA Affinity } \\
\hline & $K_{\mathrm{q}}\left(10^{14}\right)$ & $K_{\mathrm{sv}}\left(10^{6}\right)$ & $R^{2}$ & $\log K_{a}$ & $n$ & $R^{2}$ & $K_{\mathrm{q}}\left(10^{14}\right)$ & $K_{\mathrm{sv}}\left(10^{6}\right)$ & $R^{2}$ & $\log K_{a}$ & $n$ & $R^{2}$ \\
\hline Apigenin & 4.695 & 2.911 & 0.999 & 6.655 & 0.962 & 0.998 & 3.710 & 2.300 & 0.998 & 7.086 & 0.870 & 0.999 \\
\hline Naringenin & 3.100 & 1.922 & 0.999 & 6.493 & 0.974 & 0.999 & 1.408 & 0.873 & 0.996 & 6.982 & 0.925 & 0.999 \\
\hline Luteolin & 1.781 & 1.104 & 0.995 & 7.064 & 0.904 & 0.999 & 1.285 & 0.797 & 0.994 & 7.110 & 0.923 & 0.998 \\
\hline Kaempferol & 3.923 & 2.432 & 0.999 & 6.830 & 0.918 & 0.999 & 1.923 & 1.192 & 0.996 & 7.106 & 0.911 & 0.995 \\
\hline Astragalin & 0.918 & 0.569 & 0.997 & 6.234 & 0.994 & 0.993 & 1.224 & 0.759 & 0.997 & 6.359 & 0.963 & 0.998 \\
\hline Quercetin & 3.594 & 2.228 & 0.998 & 7.089 & 0.868 & 0.999 & 2.018 & 1.251 & 0.991 & 7.299 & 0.858 & 0.999 \\
\hline Taxifolin & 1.802 & 1.117 & 0.993 & 6.748 & 0.907 & 0.997 & 1.334 & 0.827 & 0.990 & 7.067 & 0.909 & 0.998 \\
\hline Isorhamnetin & 1.445 & 0.896 & 0.994 & 6.798 & 0.923 & 0.999 & 1.066 & 0.661 & 0.995 & 6.828 & 0.941 & 0.999 \\
\hline Isoquercitrin & 1.423 & 0.882 & 0.995 & 6.584 & 0.936 & 0.997 & 0.919 & 0.570 & 0.993 & 7.095 & 0.938 & 0.999 \\
\hline Hyperoside & 1.434 & 0.889 & 0.996 & 6.802 & 0.960 & 0.995 & 1.148 & 0.712 & 0.997 & 6.891 & 0.950 & 0.996 \\
\hline Rutin & 0.827 & 0.513 & 0.999 & 5.896 & 0.992 & 0.999 & 0.731 & 0.453 & 0.995 & 6.686 & 0.962 & 0.998 \\
\hline
\end{tabular}

Table 3. Effects of hydroxylation, methylation, hydrogenation, and glycosylation of flavonoids on the affinities for HSA and BSA.

\begin{tabular}{cccc}
\hline \multirow{2}{*}{ Structural Alteration } & \multirow{2}{*}{ Examples } & \multicolumn{2}{c}{ Effects (Times) } \\
\cline { 2 - 3 } & & HSA Affinity & BSA Affinity \\
\hline \multirow{2}{*}{2,3 -hydrogenation } & Apigenin $\rightarrow$ Naringenin & $1.45 \downarrow$ & $1.27 \downarrow$ \\
& Quercetin $\rightarrow$ Taxifolin & $2.19 \downarrow$ & $1.71 \downarrow$ \\
\hline \multirow{2}{*}{$3^{\prime} \mathrm{H} \rightarrow \mathrm{OH}$} & Apigenin $\rightarrow$ Luteolin & $2.56 \uparrow$ & $1.06 \uparrow$ \\
& Kaempferol $\rightarrow$ Quercetin & $1.82 \uparrow$ & $1.56 \uparrow$ \\
& Astragalin $\rightarrow$ Isoquercitrin & $2.24 \uparrow$ & $5.45 \uparrow$ \\
\hline \multirow{2}{*}{$3 \mathrm{H} \rightarrow \mathrm{OH}$} & Apigenin $\rightarrow$ Kaempferol & $1.50 \uparrow$ & $1.05 \uparrow$ \\
\hline \multirow{2}{*}{$3,3^{\prime} \mathrm{H} \rightarrow \mathrm{OH}$} & Apigenin $\rightarrow$ Quercetin & $2.72 \uparrow$ & $1.63 \uparrow$ \\
& Naringenin $\rightarrow$ Taxifolin & $7.80 \uparrow$ & $1.22 \uparrow$ \\
\hline $3^{\prime} \mathrm{OH} \rightarrow \mathrm{OCH}{ }_{3}$ & Quercetin $\rightarrow$ Isorhamnetin & $1.95 \downarrow$ & $2.96 \downarrow$ \\
\hline \multirow{2}{*}{$3-\mathrm{O}-\mathrm{glycosylation}$} & Quercetin $\rightarrow$ Isoquercitrin & $3.20 \downarrow$ & $1.60 \downarrow$ \\
& Quercetin $\rightarrow$ Hyperoside & $1.94 \downarrow$ & $2.56 \downarrow$ \\
& Quercetin $\rightarrow$ Rutin & $15.60 \downarrow$ & $4.10 \downarrow$ \\
& Kaempferol $\rightarrow$ Astragalin & $3.94 \downarrow$ & $5.58 \downarrow$ \\
\hline
\end{tabular}




\subsubsection{Hydrogenation of the $\mathrm{C}_{2}=\mathrm{C}_{3}$ Double Bond}

The $C_{2}=C_{3}$ double bond in conjugation with a 4-oxo group plays an important role for the affinity for serum albumins [46]. As shown in Table 3, the hydrogenation of the $C_{2}=C_{3}$ double bond of flavonoids decreased the binding affinities for HSA and BSA. Both naringenin and taxifolin showed lower affinities than that of apigenin and quercetin. As mentioned by Xiao, the planarity of the $\mathrm{C}$ ring in flavonoids might be important for binding interaction with proteins. Because the molecules with saturated $\mathrm{C}_{2}=\mathrm{C}_{3}$ bonds permit more twisting of the $\mathrm{B}$ ring, resulting the harder enter of hydrophobic pockets in proteins $[47,48]$.

\subsection{Relationship of Topological Polar Surface Area (TPSA) and the Affinity for HSA and BSA}

As the sum of surfaces of polar atoms in a molecule, TPSA was a good indicator in the characterization of drug absorption, including intestinal absorption, bioavailability, and blood-brain barrier penetration. A strong correlation between TPSA and transport property could be found and the compound with high TPSA could be transported [44]. The TPSA values of tested flavonoids were confirmed from PubChem Public Chemical Database. The relationships between TPSA and binding affinity of flavonoids for HSA and BSA were plotted in Figure 4. As shown in Figure 4, no direct relationship between the TPSA values and $\log K_{\mathrm{a}}$ values of flavonoids for HSA and BSA was found. However, it could be seen that the $\log K_{\mathrm{a}}$ decreased with the increasing TPSA values of flavonoids for both HSA and BSA. The flavonoids with low TPSA were bound more tightly to HSA and BSA than those with high TPSA, which was in accordance with the reports $[44,45]$.

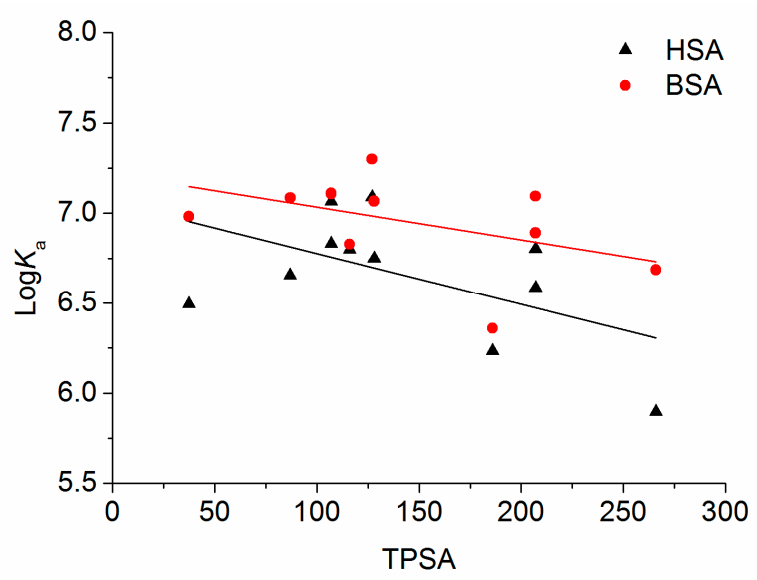

Figure 4. Relationship of TPSA with the affinities of flavonoids for HSA (black) and BSA (red).

\section{Materials and Methods}

\subsection{Chemicals and Reagents}

Human serum albumin (HSA) (96-99\%, fraction V) and bovine serum albumin (BSA) (96\%, fraction V) were purchased from GIBCO Co. (Shanghai, China). 3,5-dinitrosalicylic acid (DNS), potassium sodium tartrate tetrahydrate, soluble starch and 1,1-Diphenyl-2-picrylhydrazyl (DPPH) were acquired from Sigma-Aldrich Chemicals (St. Louis, MO, USA). Isorhamnetin (>98.0\%), Apigenin $(>98.0 \%)$, Naringenin $(>98.0 \%)$, Kaempferol $(>98.0 \%)$, Quercetin $(>98.0 \%)$, Taxifolin $(>98.0 \%)$, Luteolin ( $>96.0 \%)$, Isoquercitrin $(>98.0 \%)$, Hyperoside $(>98.0 \%)$, Astragalin $(>98.0 \%)$, and Rutin $(>98.0 \%)$ were purchased from Yuanye Biotechnology Co. (Shanghai, China). Ultrapure water (18.2 $\mathrm{M} \Omega \mathrm{cm}$ resistivity) was obtained from an ELGA water purification system (ELGA Berkefeld, Veolia, Germany). All of other chemicals were analytical grade and purchased from Sinopharm Chemical Reagent Co., Ltd. (Shanghai, China). 


\subsection{Preparation of Lotus Leaf Extracts}

Dried lotus leaf $(30.0 \mathrm{~g})$ was powdered and extracted with $300 \mathrm{~mL}$ of $90 \%$ ethanol solution at $90{ }^{\circ} \mathrm{C}$ for $3 \mathrm{~h}$ to yield the crude extract $[49,50]$. Then, the extract solution was evaporated to remove the solvent under reduced pressure. The residue ( $3.18 \mathrm{~g}$ ) was dissolved in $100 \mathrm{~mL}$ of methanol, filtered by a $0.45 \mu \mathrm{m}$ membrane and stored at $4{ }^{\circ} \mathrm{C}$ prior to use.

\subsection{Analysis of Flavonoids in Lotus Leaf Extracts}

The analysis of 11 flavonoids in lotus leaf extract was conducted through HPLC analysis using an Agilent 1260 Infinity system (Agilent Technologies Inc., Santa Clara, CA, USA). A Waters Xbridge ${ }^{\mathrm{TM}}$ $\mathrm{C}_{18}$ reverse phase column $(250 \mathrm{~mm} \times 4.6 \mathrm{~mm}$ i.d., $5 \mu \mathrm{m})$ was used as the separation column (Waters, Milford, MA, USA). The column temperature was maintained at $25^{\circ} \mathrm{C}$ and the flow rate was controlled at $0.8 \mathrm{~mL} / \mathrm{min}$. The mobile phase consisted of solvent A (water containing $0.1 \% v / v$ acetic acid) and solvent $\mathrm{B}$ (acetonitrile containing $0.1 \% v / v$ acetic acid) with gradient elution mode: $0-10 \mathrm{~min}$, $15 \% \mathrm{~B}$ and 10-45 min, 15-45\% B. The scan wavelength of diode array detector was set from 190-400 nm and the detection wavelength of chromatogram was set at $254 \mathrm{~nm}$.

\subsection{Protein Fluorescence Quenching Study}

The fluorescence spectra were recorded on a Hitachi F-7000 fluorometer (Tokyo, Japan). The fluorescence quenching method was utilized to determine the binding constants between flavonoid and protein according to previous reports [6]. $20 \mu \mathrm{L}$ of HSA or BSA solution $\left(1.0 \times 10^{-5} \mathrm{~mol} / \mathrm{L}\right)$ in phosphate buffered saline (PBS, pH 7.4) was added into a $1.0 \mathrm{~cm}$ quartz cell and then flavonoids sample or lotus leaf extract $(1.0 \mathrm{mmol} / \mathrm{L}$ or $4.0 \mathrm{mg} / \mathrm{mL}$ in methanol solution) was successively added manually with trace syringes. The intrinsic fluorescence emission spectra of HSA and BSA were recorded from 300 to $450 \mathrm{~nm}$ under an excitation wavelength of $280 \mathrm{~nm}$. The fluorescence intensities were monitored at $336 \mathrm{~nm}$ for HSA and $341 \mathrm{~nm}$ for BSA and each test was performed in triplicate.

The fluorescence quenching of HSA and BSA by flavonoids was described by the Stern-Volmer equation shown as

$$
\mathrm{F}_{0} / \mathrm{F}=1+K_{\mathrm{q}} \tau_{0}[\mathrm{Q}]=1+K_{\mathrm{sv}}[\mathrm{Q}]
$$

where $F_{0}$ is the fluorescence intensity of protein, $F$ is the fluorescence intensity in the presence of flavonoids with different concentrations, [Q] is the corresponding concentration of flavonoids, $K_{\mathrm{q}}$ is the quenching rate constant, $\tau_{0}$ is the average lifetime (6.2 ns), and $K_{\mathrm{sv}}$ is the Stern-Volmer quenching constant.

For static quenching, after the fluorescence quenching intensities at $336 \mathrm{~nm}$ for HSA and $341 \mathrm{~nm}$ for BSA were measured, the relationship between fluorescence quenching intensity and the concentration of flavonoids could be described by the binding constant formula

$$
\log \left(\mathrm{F}_{0}-\mathrm{F}\right) / \mathrm{F}=\log K_{\mathrm{a}}+n \log [\mathrm{Q}]
$$

where $\mathrm{F}_{0}$ is the fluorescence intensity of protein, $\mathrm{F}$ is the fluorescence intensity in the presence of flavonoids with different concentrations, $[Q]$ is the corresponding concentration of flavonoids, $K_{\mathrm{a}}$ is the binding constant, and $n$ is the number of binding sites per protein molecule. All the flavonoid samples showed no emission spectra in the scanned range under excitation.

\section{Conclusions}

The existence of 11 flavonoids in lotus leaf extract was confirmed in this study and 11 flavonoids showed various contents ranging from $0.063 \pm 0.009$ to $29.778 \pm 0.180 \mathrm{mg} / \mathrm{g}$ in lotus leaf. The interactions between lotus leaf extract and serum albumins completed by spectroscopic methods showed apparent quenching effect on serum albumins. Then, the structure-affinity relationships of flavonoids on binding to serum albumins were further investigated. The hydroxylation on 3 and $3^{\prime}$ 
position improved the affinities for serum albumins. The methylation on $3^{\prime}$ position of quercetin, the $\mathrm{C}_{2}=\mathrm{C}_{3}$ double bonds of apigenin and quercetin and the glycosylations of quercetin and kaempferol all decreased the affinities for serum albumins. The results demonstrated that the hydrogen bond force played an important role in binding flavonoids to serum albumins.

Acknowledgments: This work was financially supported by Talent Introduction Project of Hubei Normal University in 2015.

Author Contributions: L.L. conceived and designed the experiments; X.T. and P.T. performed the experiments and analyzed the data; L.L. and X.T. wrote the paper.

Conflicts of Interest: The authors declare no conflict of interest.

\section{References}

1. Xiao, J.; Kai, G.; Ni, X.; Yang, F.; Chen, X. Interaction of natural polyphenols with $\alpha$-amylase in vitro: Molecular property-affinity relationship aspect. Mol. Biosyst. 2011, 7, 1883-1890. [CrossRef] [PubMed]

2. Xiao, J.; Cao, H.; Wang, Y.; Yamamoto, K.; Wei, X. Structure-affinity relationship of flavones on binding to serum albumins: Effect of hydroxyl groups on ring A. Mol. Nutr. Food Res. 2010, 54, S253-S260. [CrossRef] [PubMed]

3. Xiao, J.; Ni, X.; Kai, G.; Chen, X. Advance in dietary polyphenols as aldose reductases inhibitors: Structure-activity relationship aspect. Crit. Rev. Food Sci. Nutr. 2015, 55, 16-31. [CrossRef] [PubMed]

4. Hou, J.; Wang, Z.; Yue, Y.; Li, Q.; Shao, S. Spectroscopic analysis on structure-affinity relationship in the interactions of different oleanane-type triterpenoids with bovine serum albumin. Luminescence 2015, 30, 780-789. [CrossRef] [PubMed]

5. Xiao, J.; Capanoglu, E.; Jassbi, A.R.; Miron, A. Advance on the flavonoid C-glycosides and health benefits. Crit. Rev. Food Sci. Nutr. 2016, 56, S29-S45. [CrossRef] [PubMed]

6. Peng, X.; Qi, W.; Huang, R.; Su, R.; He, Z. Elucidating the influence of gold nanoparticles on the binding of salvianolic acid $\mathrm{B}$ and rosmarinic acid to bovine serum albumin. PLoS ONE 2015, 10, e0118274. [CrossRef] [PubMed]

7. Zhao, X.; Shen, J.; Chang, K.J.; Kim, S.H. Comparative analysis of antioxidant activity and functional components of the ethanol extract of lotus (Nelumbo nucifera) from various growing regions. J. Agric. Food Chem. 2014, 62, 6227-6235. [CrossRef] [PubMed]

8. Huang, C.F.; Chen, Y.W.; Yang, C.Y.; Lin, H.Y.; Way, T.D.; Chiang, W.; Liu, S.H. Extract of lotus leaf (Nelumbo nucifera) and its active constituent catechin with insulin secretagogue activity. J. Agric. Food Chem. 2011, 59, 1087-1094. [CrossRef] [PubMed]

9. Lin, H.Y.; Kuo, Y.H.; Lin, Y.L.; Chiang, W. Antioxidative effect and active components from leaves of lotus (Nelumbo nucifera). J. Agric. Food Chem. 2009, 57, 6623-6629. [CrossRef] [PubMed]

10. Morikawa, T.; Kitagawa, N.; Tanabe, G.; Ninomiya, K.; Okugawa, S.; Motai, C.; Kamei, I.; Yoshikawa, M.; Lee, I.J.; Muraoka, O. Quantitative determination of alkaloids in lotus flower (flower buds of Nelumbo nucifera) and their melanogenesis inhibitory activity. Molecules 2016, 21, 930. [CrossRef] [PubMed]

11. Zheng, Y.; Wang, Q.; Zhuang, W.; Lu, X.; Miron, A.; Chai, T.T.; Zheng, B.; Xiao, J. Cytotoxic, antitumor and immunomodulatory effects of the water-soluble polysaccharides from lotus (Nelumbo nucifera Gaertn.) seeds. Molecules 2016, 21, 1465. [CrossRef] [PubMed]

12. Li, F.; Sun, X.Y.; Li, X.W.; Yang, T.; Qi, L.W. Enrichment and separation of quercetin-3-O- $\beta$-D-glucuronide from lotus leaves (Nelumbo nucifera Gaertn.) and evaluation of its anti-inflammatory effect. J. Chromatogr. B 2017, 1040, 186-191. [CrossRef] [PubMed]

13. Ye, L.H.; Kong, L.T.; Yan, M.Z.; Cao, F.R.; Wang, L.S.; Liao, Y.H.; Pan, R.L.; Chang, Q. Lotus leaf alkaloid fraction can strongly inhibit CYP2D6 isoenzyme activity. J. Ethnopharmacol. 2016, 194, 913-917. [CrossRef] [PubMed]

14. Zhu, M.Z.; Wu, W.; Jiao, L.L.; Yang, P.F.; Guo, M.Q. Analysis of Flavonoids in Lotus (Nelumbo nucifera) Leaves and their antioxidant activity using macroporous resin chromatography coupled with LC-MS/MS and antioxidant biochemical assays. Molecules 2015, 20, 10553. [CrossRef] [PubMed]

15. Chen, S.; Zheng, Y.; Fang, J.B.; Liu, Y.L.; Li, S.H. Flavonoids in lotus (Nelumbo) leaves evaluated by HPLC-MSn at the germplasm level. Food Res. Int. 2013, 54, 796-803. [CrossRef] 
16. Chen, S.; Fang, L.; Xi, H.; Guan, L.; Fang, J.; Liu, Y.; Wu, B.; Li, S. Simultaneous qualitative assessment and quantitative analysis of flavonoids in various tissues of lotus (Nelumbo nucifera) using high performance liquid chromatography coupled with triple quad mass spectrometry. Anal. Chim. Acta 2012, 724, 127-135. [CrossRef] [PubMed]

17. Chen, S.; Wu, B.H.; Fang, J.B.; Liu, Y.L.; Zhang, H.H.; Fang, L.C.; Guan, L.; Li, S.H. Analysis of flavonoids from lotus (Nelumbo nucifera) leaves using high performance liquid chromatography/photodiode array detector tandem electrospray ionization mass spectrometry and an extraction method optimized by orthogonal design. J. Chromatogr. A 2012, 1227, 145-153. [CrossRef] [PubMed]

18. Tang, F.; Xie, Y.; Cao, H.; Yang, H.; Chen, X.; Xiao, J. Fetal bovine serum influences the stability and bioactivity of resveratrol analogues: A polyphenol-protein interaction approach. Food Chem. 2017, 219, 321-328. [CrossRef] [PubMed]

19. He, L.L.; Wang, Z.X.; Wang, Y.X.; Liu, X.P.; Yang, Y.J.; Gao, Y.P.; Wang, X.; Liu, B.; Wang, X. Studies on the interaction between promethazine and human serum albumin in the presence of flavonoids by spectroscopic and molecular modeling techniques. Colloids Surf. B 2016, 145, 820-829. [CrossRef] [PubMed]

20. Barreca, D.; Laganà, G.; Toscano, G.; Calandra, P.; Kiselev, M.A.; Lombardo, D.; Bellocco, E. The interaction and binding of flavonoids to human serum albumin modify its conformation, stability and resistance against aggregation and oxidative injuries. BBA Gen. Subjects 2017, 1861 Part B, 3531-3539. [CrossRef] [PubMed]

21. Li, S.; Tang, L.; Bi, H. Study on the interaction between pelargonidin-3-O-glucoside and bovine serum albumin using spectroscopic, transmission electron microscopy and molecular modeling techniques. Luminescence 2016, 31, 442-452. [CrossRef] [PubMed]

22. Poureshghi, F.; Ghandforoushan, P.; Safarnejad, A.; Soltani, S. Interaction of an antiepileptic drug, lamotrigine with human serum albumin (HSA): Application of spectroscopic techniques and molecular modeling methods. J. Photochem. Photobiol. B 2017, 166, 187-192. [CrossRef] [PubMed]

23. Wang, X.; Liu, Y.; He, L.L.; Liu, B.; Zhang, S.Y.; Ye, X.; Jing, J.J.; Zhang, J.F.; Gao, M.; Wang, X. Spectroscopic investigation on the food components-drug interaction: The influence of flavonoids on the affinity of nifedipine to human serum albumin. Food Chem. Toxicol. 2015, 78, 42-51. [CrossRef] [PubMed]

24. Xiang, Y.; Duan, L.; Ma, Q.; Lv, Z.; Ruohua, Z.; Zhang, Z. Fluorescence spectroscopy and molecular simulation on the interaction of caffeic acid with human serum albumin. Luminescence 2016, 31, 1496-1502. [CrossRef] [PubMed]

25. Munteanu, A.C.; Badea, M.; Olar, R.; Silvestro, L.; Dulea, C.; Negut, C.D.; Uivarosi, V. Synthesis and structural investigation of new bio-relevant complexes of lanthanides with 5-hydroxyflavone: DNA binding and protein interaction studies. Molecules 2016, 21, 1737. [CrossRef] [PubMed]

26. Rimac, H.; Debeljak, Z.; Sakic, D.; Weitner, T.; Gabricevic, M.; Vrcek, V.; Zorc, B.; Bojic, M. Structural and electronic determinants of flavonoid binding to human serum albumin: An extensive ligand-based study. RSC Adv. 2016, 6, 75014-75022. [CrossRef]

27. Fu, L.; Sun, Y.; Ding, L.; Wang, Y.; Gao, Z.; Wu, Z.; Wang, S.; Li, W.; Bi, Y. Mechanism evaluation of the interactions between flavonoids and bovine serum albumin based on multi-spectroscopy, molecular docking and Q-TOF HR-MS analyses. Food Chem. 2016, 203, 150-157. [CrossRef] [PubMed]

28. Roy, A.S.; Dinda, A.K.; Pandey, N.K.; Dasgupta, S. Effects of urea, metal ions and surfactants on the binding of baicalein with bovine serum albumin. J. Pharm. Anal. 2016, 6, 256-267. [CrossRef]

29. Khan, M.K.; Rakotomanomana, N.; Dufour, C.; Dangles, O. Binding of citrus flavanones and their glucuronides and chalcones to human serum albumin. Food Funct. 2011, 2, 617-626. [CrossRef] [PubMed]

30. Papadopoulou, A.; Green, R.J.; Frazier, R.A. Interaction of flavonoids with bovine serum albumin: A fluorescence quenching study. J. Agric. Food Chem. 2005, 53, 158-163. [CrossRef] [PubMed]

31. Shi, J.; Cao, H. Molecular structure-affinity relationship of dietary flavonoids for bovine serum albumin. Rev. Bras. Farmacogn. 2011, 21, 594-600. [CrossRef]

32. Namazi, M.; Amir Ali Akbari, S.; Mojab, F.; Talebi, A.; AlaviMajd, H.; Jannesari, S. Effects of citrus aurantium (bitter orange) on the severity of first-stage labor pain. Iran. J. Pharm. Res. 2014, 13, 1011-1018. [PubMed]

33. Ikeda, M.; Ueda-Wakagi, M.; Hayashibara, K.; Kitano, R.; Kawase, M.; Kaihatsu, K.; Kato, N.; Suhara, Y.; Osakabe, N.; Ashida, H. Substitution at the C-3 position of catechins has an influence on the binding affinities against serum albumin. Molecules 2017, 22, 314. [CrossRef] [PubMed]

34. Cao, H.; Chen, L.; Xiao, J. Binding Citrus flavanones to human serum albumin: Effect of structure on affinity. Mol. Biol. Rep. 2011, 38, 2257-2262. [CrossRef] [PubMed] 
35. Dufour, C.; Dangles, O. Flavonoid-serum albumin complexation: Determination of binding constants and binding sites by fluorescence spectroscopy. BBA Gen. Subjects 2005, 1721, 164-173. [CrossRef] [PubMed]

36. Pal, S.; Saha, C. A review on structure-affinity relationship of dietary flavonoids with serum albumins. J. Biomol. Struct. Dyn. 2014, 32, 1132-1147. [CrossRef] [PubMed]

37. Fu, M.; Xu, Y.; Chen, Y.; Wu, J.; Yu, Y.; Zou, B.; An, K.; Xiao, G. Evaluation of bioactive flavonoids and antioxidant activity in Pericarpium Citri Reticulatae (Citrus reticulata 'Chachi') during storage. Food Chem. 2017, 230, 649-656. [CrossRef] [PubMed]

38. Khan, S.; Khan, H.; Ali, F.; Ali, N.; Khan, F.U.; Khan, S.U. Antioxidant, cholinesterase inhibition activities and essential oil analysis of Nelumbo nucifera seeds. Nat. Prod. Res. 2016, 30, 1335-1338. [CrossRef] [PubMed]

39. Tao, Y.; Zhang, Y.; Wang, Y.; Cheng, Y. Hollow fiber based affinity selection combined with high performance liquid chromatography-mass spectroscopy for rapid screening lipase inhibitors from lotus leaf. Anal. Chim. Acta 2013, 785, 75-81. [CrossRef] [PubMed]

40. Liu, Y.; Ma, S.S.; Ibrahim, S.A.; Li, E.H.; Yang, H.; Huang, W. Identification and antioxidant properties of polyphenols in lotus seed epicarp at different ripening stages. Food Chem. 2015, 185, 159-164. [CrossRef] [PubMed]

41. Ye, L.H.; He, X.X.; Kong, L.T.; Liao, Y.H.; Pan, R.L.; Xiao, B.X.; Liu, X.M.; Chang, Q. Identification and characterization of potent CYP2D6 inhibitors in lotus leaves. J. Ethnopharmacol. 2014, 153, 190-196. [CrossRef] [PubMed]

42. Zhang, X.; Lin, Y.; Liu, L.; Lin, C. Study on the synthesis of sulfonamide derivatives and their interaction with bovine serum albumin. Luminescence 2015, 30, 269-279. [CrossRef] [PubMed]

43. Xiao, J.; Suzuki, M.; Jiang, X.; Chen, X.; Yamamoto, K.; Ren, F.; Xu, M. Influence of B-ring hydroxylation on interactions of flavonols with bovine serum albumin. J. Agric. Food Chem. 2008, 56, 2350-2356. [CrossRef] [PubMed]

44. Xiao, J.; Chen, T.; Cao, H.; Chen, L.; Yang, F. Molecular property-affinity relationship of flavanoids and flavonoids for HSA in vitro. Mol. Nutr. Food Res. 2011, 55, 310-317. [CrossRef] [PubMed]

45. Xiao, J.; Zhao, Y.; Wang, H.; Yuan, Y.; Yang, F.; Zhang, C.; Kai, G. Non-covalent interaction of dietary polyphenols with total plasma proteins of type II diabetes: Molecular structure/property-affinity relationships. Integr. Biol. 2011, 3, 1087-1094. [CrossRef] [PubMed]

46. Xiao, J. 226-Stability of dietary polyphenols under cell culture conditions. Free Radic. Biol. Med. 2014, 76, S96.

47. Bose, A. Interaction of tea polyphenols with serum albumins: A fluorescence spectroscopic analysis. J. Lumin. 2016, 169 Part $A, 220-226$. [CrossRef]

48. Xiao, J.; Zhao, Y.; Wang, H.; Yuan, Y.; Yang, F.; Zhang, C.; Yamamoto, K. Noncovalent interaction of dietary polyphenols with common human plasma proteins. J. Agric. Food Chem. 2011, 59, 10747-10754. [CrossRef] [PubMed]

49. Liu, L.L.; Cen, Y.; Liu, F.; Yu, J.G.; Jiang, X.Y.; Chen, X.Q. Analysis of alpha-amylase inhibitor from corni fructus by coupling magnetic cross-linked enzyme aggregates of alpha-amylase with HPLC-MS. Chromatogr. B 2015, 995, 64-69. [CrossRef] [PubMed]

50. Alam, P.; Parvez, M.K.; Arbab, A.H.; Al-Dosari, M.S. Quantitative analysis of rutin, quercetin, naringenin, and gallic acid by validated RP- and NP-HPTLC methods for quality control of anti-HBV active extract of Guiera senegalensis. Pharm. Biol. 2017, 55, 1317-1323. [CrossRef] [PubMed]

Sample Availability: Not available. 